\title{
Éticas Esteticamente Fundadas e a Filosofia de Nietzsche ${ }^{1}$
}

\author{
Claus Zittel|
}

De fabulações sobre a "unidade", a
"alma", a "pessoa", [disso] nós nos proi-
bimos por ora
(Anotação póstuma 1885, KSA $11,37[4]$ )

O confesso nietzscheano Michel Foucault formulou de modo pregnante, em uma de suas entrevistas tardias, o seguinte: "Do pensamento de que o si-próprio [Selbst] não nos é dado, uma consequência prática, a meu ver, pode ser extraída: nós temos que nos justificar [begründen], nos constituir [herstellen], nos organizar [anordnen]". ${ }^{3}$

Foucault não estava só nessa exigência de um estético dar- se-a-si-mesmo-uma-forma [einer ästhetischen Selbstgestaltung]: com direto apelo a Nietzsche, foram apresentadas desde a década de 70, em diversos âmbitos, concepções para uma ética do indivíduo sob o título de uma "filosofia da arte de viver [Philosophie der Lebenskunst]", de uma "estética da existência", de uma ética do "dar-se-a-si-mesmo-umaforma" (Foucault ${ }^{4}$, Nehamas, MacIntyre, Gerhardt, Schmid, Nuss-

\footnotetext{
${ }^{1}$ Agradeço a Bettina Hartmann, Martin Saar e Werner Stegmaier pelas críticas a uma primeira versão do meu texto. [Tradução para o português realizada por André Luis Muniz Garcia (Professor do Departamento de Filosofia da UnB).]

${ }^{2}$ Professor da Universidade de Stuttgart, Alemanha. Este texto foi originalmente publicado em: NietzscheStudien vol. 32, 2003, pp. 103-123 [Nota do tradutor].

${ }^{3}$ FOUCAULT, Michel. Sex als Moral. Gespräch mit Hubert Dreyfus und Paul Rabinow. in: FOUCAULT, Michel. Von der Freundschaft. Frankfurt am Main: 1984, pp. 69-93.

${ }^{4}$ Cf. FOUCAULT, Michel. Der Geburt der Lüste. Frankfurt am Main: 1990, p. 18. Wolfgang Detel chega, no entanto, ao resultado, em seu Macht, Moral, Wissen: Foucault und die klassische Antike. Frankfurt am Main: 1998, passim, de que Foucault subestima o significado da dimensão estética para uma boa conduta da vida (ver p. 78 e 275). Pierre Hadot, referindo-se a esse estudo sobre a ética antiga em Foucault, dá, em resposta, um passo adiante e reconhece na interpretação esteticizante de Foucault da ética antiga um moderno mal-entendido. Contrariamente às intenções de Foucault, a ética estoica não está centrada [na figura de um] si-próprio [Selbst], nem há nela liberdade de escolha pessoal, algo sugerido por Foucault, entre diferenciados modos de descrição de si próprio [verschiedenen Selbstbeschreibungen] como fundamento de um deliberado dar-se-a-si-mesmo-uma-forma [willentlichen Selbstgestalgungen]. "Na realidade, a escolha pessoal encontra-se no contrário, na adesão a uma forma de vida definida, seja ao estoicismo ou ao epicurismo, uma que pareça adequada à razão". (HADOT, Pierre. Überlegungen zum Begriff der "Selbststruktur". in: EWALD, François, WALDENFELS, Bernhard (org.): Spiele der Wahrheit. Michel Foucaults Denken. Frankfurt am Main: 1991, pp. 219-228, aqui p. 225. Mesmo se a reconstrução de Foucault da forma de vida artística for historicamente falsa, ela poderia ser sistematicamente sustentável. Isso será provado a seguir.
} 
baum), e até mesmo de uma [ética da] "invenção de si [Selbsterfidung]" (Rorty), as quais associam, de diferentes maneiras, estética e ética. 5

Minhas considerações, a seguir, miram isto: elucidar algumas substanciais dificuldades que se apresentam nessas tentativas de associar ética e estética, por um lado, ante o pano de fundo da psicologia de Nietzsche e, por outro, com relação à compreensão da arte, algo que fundamentaria implicitamente tais tentativas.

$\mathrm{Na}$ exposição de elementos da psicologia de Nietzsche, em especial em sua crítica ao conceito tradicional de consciência ${ }^{6}$, não reivindico de modo algum originalidade na interpretação. Gostaria tão só de confrontar essas conhecidas posições com diferentes programas da arte de viver [Lebenskunst], a fim de indagar seus fundamentos nos textos do próprio Nietzsche. Nesse contexto, esbo- çarei, além disso, diferenças iniciais quanto à forma dos conceitos ética e estética, com o intuito de mostrar que éticas dificilmente, ou quase nunca, se deixam fundir esteticamente (de todo modo, apenas marginalmente quando se apela a Nietzsche e por motivos que precisam ser diferenciados). Aliás: a representação clássica dos termos Form e Gestaltung, que fundamentam as éticas da arte de viver [Ethiken der Lebenskunst], são, na minha hipótese, questionadas por Nietzsche de múltiplos modos, tanto esteticamente quanto psicologicamente. Da variedade de objeções possíveis que podem ser trazidas à tona contra as éticas do dar-sea-si-mesmo-uma-forma [Ethiken der Selbstgestaltungen], escolherei em primeiro lugar aquelas que justamente miram uma interface entre ética e estética.

Outras tentativas de se filiar às considerações éticas de Nietzs-

\footnotetext{
${ }^{5}$ Cf. NEHAMAS, Alexander. Nietzsche: life as literature. Harvard: 1985; também dele, The art of living. Socratic reflections from Plato to Foucault. Berkeley: 1998; MACINTYRE, Alasdair: After virtue. Notre Dame: 1981; NUSSBAUM, Martha. Love's knowledge. Essays on philosophy and literature. Oxford: 1990; REUBER, Rudolf: Ästhetische Lebensformen bei Nietzsche. München, 1988; SCHMID, Wilhelm. Auf der Suche nach einer neuen Lebenskunst: Die Frage nach dem Grund und die Neubegründung der Ethik bei Foucault. Frankfurt am Main: 1991; do mesmo autor. "Das Dasein - ein Kunstwerk: Zum Verhältnis von Kunst und Lebenskunst bei Nietzsche". in: Deutsche Zeitschrift für Philosophie 6, 1991, pp. 650-660; também do mesmo autor. "Uns selbst gestalten. Zur Philosophie der Lebenskunst bei Nietzsche". in: Nietzsche-Studien 21: 1992, pp. 50-62. RORTY, Richard. Contingency, irony, solidarity. Cambridge: 1989. Comparar também a classificação de Nietzsche na rubrica "perfeccionista estética da existência [Perfektionistische Ästhetik der Existenz]" segundo Josef Früchtl, in: Ästhetische Erfahrung und moralisches Urteil. Frankfurt am Main: 1996, pp. 157-177.

${ }^{6}$ Sobre o conceito de consciência em Nietzche, ver ABEL, Günter. "Bewusstsein — Sprache — Natur: Nietzsches Philosophie des Geites". in: Nietzsche-Studien 30, 2001, pp. 1-43. SIMON, Josef. "Das Problem des Bewusstseins bei Nietzsche und der traditionelle Bewusstseinsbegriff". in: DJURIC, Mihailo, SIMON, Josef (org.). Zur Aktualität Nietzsches. Würzburg: 1984, p. 17-33. SCHLIMGEN, Erwin. Nietzsches Theorie des Bewusstseins. Berlin/New York: 1999.
} 
che, mas que, em sua justificação sistemática, não estabelecem relação com a arte, estão do mesmo modo, por um lado, já diante de um problema, a saber: como elas deveriam proceder com a psicologia de Nietzsche? Por outro, devem responder à fundamental questão, qual seja, se é legítimo no quadro de uma interpretação de Nietzsche deixar de fora justamente a dimensão da arte? No entanto, não há como me ocupar neste artigo delas..$^{7}$

Em ciente antagonismo contra algumas posições confiáveis da pesquisa Nietzsche, minhas teses são:

\section{As considerações psicológicas} e estéticas de Nietzsche não são conciliáveis com interpretações éticas. Nietzsche apresenta uma psicologia que é ruinosa à qualquer ética normativa; ele também advoga uma estética antiética.
2. Uma estética da existência atribuída a Nietzsche basearse-ia em conceitos insustentáveis. Pois tanto o conceito de forma estética quanto o conceito de "forma de vida [Lebensform]", que àquela [concepção] subjaz, sugere representações de unidade que, com relação a Nietzsche, não param de pé. A unidade da obra de arte e a [noção] forma de vida [Gestalt des Lebens] não se deixam, sem mais, equacionar.

3. Vida e arte deixam-se associar, em Nietzsche, apenas em um ponto, que, por sua vez, se subtrai às éticas da arte de viver qualquer base.

Como mencionado, as éticas do dar-se-a-si-mesmo-uma-forma apresentam-se, de certa maneira, de modo não uniforme. Éticas concebidas esteticamente, no encalço de Foucault, opõem-se a po-

\footnotetext{
${ }^{7}$ Uma visão panorâmica, que vale a pena mencionar, sobre as mais recentes concepções éticas afeitas a Nietzsche, pode ser encontrada na literatura investigada em SALEHI, David, GÜNZEL, Stephan. "Nietzsches >konstruktiver Ethik in der Diskussion". in: Nietzsche-Studien 32, 2002, pp. 368-381.

${ }^{8}$ Por Foucault são orientadas, por exemplo, as interpretações de Wilhelm Schmid e Alexander Nehamas; posições neoaristotélicas são representadas por MacIntyre e Nussbaum (ver nota anterior). Contrários são os esforços de Friedrich Kaulbach, Volker Gerhardt e Birgit Recki, Beatrix Himmelmann e Michael Steinmann (os dois últimos, no entanto, sem qualquer referência à estética), todos buscam conectar Nietzsche à tradição da ética kantiana. Cf. KAULBACH, F. Sprachen der ewigen Wiederkunft. Die Denksituationen des Philosophen Nietzsche und ihre Sprachstile. Würzburg: 1985; do mesmo autor: Nietzsches Idee einer Experimentalphilosophie. Köln: 1980; também dele: Philosophie des Perspektivismus. Tübingen: 1990; GERHARDT, Volker: "Die Moral des Immoralismus. Nietzsches Beitrag zu einer Grundlegung der Ethik". in: SALAQUARDA, Jörg (org.): Krisis der Metaphysik. Berlin: 1989. pp. 417-447; dele também: "Selbstbegründung. Nietzsches Moral der Individualität". in: Nietzsche-Studien 21, 1992. pp. 2849; ainda deste autor: Selbstbestimmung. Das Prinzip der Individualität. Stuttgart 1999; HIMMELMANN, Beatrix: Freiheit und Selbstbewußtsein. Zu Nietzsches Philosophie der Subjektivität. Freiburg im Breisgau: 1996; STEIMANN, Michael: Die Ethik Friedrich Nietzsches. Berlin/New York: 2000; RECKI, Birgit: “"Artisten-Metaphysik” und ästhetisches Ethos. Friedrich Nietzsche über Ästhetik und Ethik". In: KERN, Andrea/SONDEREGGER, Ruth (orgs.): Falsche Gegensätze. Zeitgenössische Positionen zur philosophischen Ästhetik. Frankfurt am Main: 2002, pp. 262-285; também da autora: "Das ästhetische Ethos des Schaffenden. Friedrich Nietzsche über Kunst und Lebenskunst". in:
} 
sições aristotélicas ou kantianas. $]^{8}$ Elas buscam revitalizar a ética, porquanto remetem ou a modelos antigos da boa arte de viver $?^{9}$ ou, em geral, a modelos estéticos para o dar-se uma forma [Formgebung] (Rorty).

Em outros prevalece uma possível universalização do modelo ético-estético como princípio. Todas essas posições ${ }^{10}$ podem ser reunidas pela convicção segundo a qual com ajuda de modelos e categorias estéticas poder-se-ia corrigir e superar déficits efetivos ou pressupostos de uma filosofia moral "clássica" (quero dizer: kantiana), entendida aqui como restritiva e distante do cotidiano.11 Postulado restaria aqui a possibilidade de abranger todos os mo- dos da vida concreta de proceder eticamente e de integrar-se a um conceito capaz de gerar unidade, um modo não-restritivo e não-normativo, portanto, um modo "estético". Conseguir alcançar modos de viver que sejam ativos [Lebensvollzüge] é algo concebido mais ou menos estritamente como forma de definir a si próprio, como autointerpretação, autodescoberta, constituição de si, cultivo de si, autocriação ou invenção de si próprio, autodeterminação, como forma de comandar a si próprio e autolegislar-se. O denominador comum encontrase no assemelhar a unidade da vida humana à unidade de uma obra de arte. Comparáveis devem elas ser no sentido de que

\footnotetext{
Jahrbuch des Künstlerhauses Schloß Balmoral. Mainz: 1999, pp. 215-237.

${ }^{9}$ MACINTYRE, A. Der Verlust der Tugend [edição alemã de After virtue]. Frankfurt am Main: 1995, p. 159 ss. Martha Nussbaum, por exemplo, afirma que a "verdadeira proposta" de Nietzsche assentar-se-ia em levar adiante uma "revivência dos valores estoicos do autodomínio [Selbstbeherrschung] e do cultivo de si [Selbstbildung] dentro de um contexto pós-cristão e pós-romântico". NUSSBAUM, Martha. "Mitleid und Gnade. Nietzsches Stoizismus". in: Deutsche Zeitschrift für Philosophie 5, 1993, pp. 831-858, aqui p. 832. Como comprovação da tentativa de Nietzsche de associar a posição estoica e a tomada de consciência de si próprio, ela (idem, p. 845) introduz um aforismo de Aurora: "Estoicos - Há uma serenojovialidade do estoico, quando ele se sente confinado a um cerimonial que ele mesmo prescreveu à sua transformação, ele se delicia nisso como um senhor". (Aurora 251). Tal tentativa de tratar o conceito de consciência em Nietzsche sem qualquer problematização será criticado por mim a seguir.

${ }^{10}$ Algumas recentes discussões sobre a estética da existência no pensamento de Nietzsche encontram-se em: SCHEER, Brigitte: "Das Verhältnis von Ästhetik und Ethik im Denken Nietzsches". in: GREINER, Bernhard, MOOG-GRÜNEWALD, Maria (orgs.): Etho-Poietik. Ethik und Ästhetik im Dialog. Erwartungen, Forderungen, Abgrenzungen. Bonn: 1998, pp 51-68; THOMÄ, Dieter: Erzähle dich selbst. Lebensgeschichte als philosophisches Problem. München: 1998, pp 140-156; KALB, Christoph: Desintegration. Studien zu Nietzsches Leib- und Sprachphilosophie. Frankfurt am Main 2000, capítulo 7 (ver minha recensão a este livro em: Nietzsche-Studien 30, 2001, pp. 505509); SAAR, Martin: "Der Stoff des Lebens. Lebenskunst, Ethik und Immanenz". in: ECHTERHOFF, Gerald, EGGERS, Michael (orgs.): Der Stoff, an dem wir hängen. Faszination und Selektion von Material in den Kulturwissenschaften. Würzburg: 2002, pp. 31-42; BRUSOTTI, Marco: Die Leidenschaft der Erkenntnis. Philosophie und ästhetische Lebensgestaltung bei Nietzsche von ,Morgenröthe' bis ,Also sprach Zarathustra'. Berlin/New York: 1997; MENCKE, Christoph: "Distanz und Experiment. Zu zwei Aspekten ethischer Freiheit bei Nietzsche". in: Deutsche Zeitschrift für Philosophie 41, 1993, pp. 61-77.

${ }^{11}$ Com Martin Seel pode-se também interpretar, inversamente, a conjuntura da noção de arte de viver tanto como expressão quanto como resultado de uma crise da ética clássico-moderna, que teria obtido sua força justo do conceito de autonomia em detrimento de questões sobre modos concretos de conduzir a vida. SEEL, Martin. Ethisch-Ästhetische Studien. Frankfurt am Main: 1996, p. 11 ss.
} 
a vida seja concebida, como um todo, enquanto obra de arte ou no sentido de que a vida encontra aí, no tornar-se uma obra de arte, sua perfeição [Vollendung]. ${ }^{12}$ Aqui parte-se de modo evidente do fato de que a arte pode ser um modelo para a constituição do sipróprio [Gestaltung des Selbst] e que o si-próprio deixa-se constituir de modo autônomo e consciente. Critério dessa equiparação não é a dimensão sensível da obra de arte, mas sim sua estrutura conceitual.

À luz da filosofia de Nietzsche, entretanto, esta perspectiva é, em primeiro lugar, questionável, quer dizer, de que poder-se-ia dispor de modo voluntário de uma vida autêntica [über das eigene Leben verfügen], de que poder-se-ia ter seu controle e estilizá-la conscientemente como unidade; segundo, a compreensão da unidade estética aqui subjacente é dramaticamente simplista, e, em terceiro lugar, é contestável se a unidade, por um lado, da vida, por outro, da obra de arte, podem ser equiparadas uma com a outra, e se sim, em qual aspecto. ${ }^{13}$

\section{Formas do indivíduo}

O jovem Nietzsche propõe uma analogia entre o conceito de forma [Form] e o de indivíduo: "Um conceito semelhante ao de forma é o de indivíduo" (Anotação póstuma 1867 - 1868. BAW ${ }^{14}$ 3, p. 387). Essa afirmação é feita, todavia, no contexto de uma discussão cético-cognitiva e crítica, do ponto de vista da linguagem, com Kant. Ambos os conceitos deveriam ser desmascarados como grosseiras abstrações falsificadoras, por meio das quais nosso obtuso intelecto tem que proceder. $\mathrm{Na}$ "verdade não pode existir uma forma, pois em cada momento apresenta-se algo que é infinito" (ibidem). Por consequência, é preciso guardar-se ante uma compreensão simplificadora do modo como se concebe a unidade: "Falase de organismos", esclarece $\mathrm{Ni}$ etzsche, "da mesma maneira como de unidades e funções teleológicas [Zweckcentren]. Porém, há unidades apenas para nosso intelecto. Cada indivíduo contém em si uma infinitude de indivíduos vivos" (ibidem, p. 387). Tardiamente também Nietzsche fala disto, a saber, que o "eu" não pode

\footnotetext{
${ }^{12}$ Cf. Idem, p. 20 ss.

${ }^{13}$ Martin Seel problematiza, em primeiro lugar, um dos lados dessa equiparação, a da unidade da obra de arte e comporta-se de modo moderado com a forma da individualidade. No todo, ele permanece devedor de um télos concebido de modo ético-individual.

${ }^{14}$ BAW abrevia aqui: NIETZSCHE, F. Historisch-Kritische Gesamtausgabe Werke. (org.). Hans Joachim Mette und Karl Schlechta München: DTV, 1933. [Nota do tradutor]
} 
ser compreendido como uma entidade isolada em detrimento dos impulsos, mas sim como "uma pluralidade de forças individuais, das quais ora essa, ora aquela está em primeiro plano" (Anotação póstuma 1880, KSA ${ }^{15} 9$, 6[67]). "O homem" é "uma multiplicidade de forças": "O conceito de "indivíduo" é falso" (Anotação póstuma 1885, KSA 11, 34[123]).

A perspectiva-guia de Nietzsche é a de que o organismo é um conglomerado de forças que contra-atacam-se de múltiplas formas, um conglomerado que integra continuamente unidades cada vez maiores por razões pragmáticas. Tais unidades são altamente precárias, quando se busca nelas um ponto de partida para uma conceitualização ética. E isso não é diferente com a consciência e o si-próprio. O status transitório e ocasional das unidades geradas, tal como a autoconsciência e o autoconhecimento, é um drástico limitador.

A consciência é comparada por Nietzsche a uma autoridade so- berana (Herrscher), que, no entanto, não tem qualquer ciência dos procedimentos que acontecem em seus domínios. As interações que aí ocorrem tem que permanecer em geral opacas. De acordo com Nietzsche, em uma conhecida passagem, "a assim chamada consciência, toda ela, [é] um comentário mais ou menos fantástico sobre um texto desconhecido, talvez incognoscível, porém já preenchido" (Aurora 19; cf. A gaia ciência 333). Tudo que se torna consciente é resultado do que aparece apenas na superfície ${ }^{16}$ de um ativo e oculto acontecer pulsional: "Todo pensamento, todo sentimento, todo querer não nasceu de um impulso determinado, mas sim é um estado geral, uma superfície ampla que envolve toda a consciência e que é resultado de uma estabilização de poder momentâneo de todos os impulsos que nos constituem quer dizer, tanto do impulso dominante quanto dos que o obedecem e a ele resistem" (Anotação póstuma 1886, KSA 12, 1[61]).

\footnotetext{
${ }^{15}$ KSA abrevia aqui: NIETZSCHE, F. Sämtliche Werke: Kritische Studienausgabe in 15 Bänden. (org.). G. Colli u. M. Montinari. Berlin/New York: DTV \& Walter de Gruyter, 1999. [Nota do tradutor]

${ }^{16}$ Sobre a concepção de superfície em Nietzsche, cf. STEGMAIER, W. Nietzsches Zeichen. in: Nietzsche-Studien 29, 2000, p. 53 ss.

${ }^{17}$ Cf. ABEL, Günter: "Nominalismus und Interpretation. Die Überwindung der Metaphysik im Denken Nietzsches". In: SIMON, Josef (org.): Nietzsche und die philosophische Tradition. Würzburg: 1985, pp. 35-89. SCHLIMGEN, E. Nietzsches Theorie des Bewußtseins, p. 68 ss. Ver especialmente ABEL, Günter: "Bewußtsein - Sprache Natur", p. 17: "Respectivamente, organismo e orgânico em Nietzsche são concebidos como uma estrutura organizada, na qual o estado de consciência, o tornar-se consciente e todos os demais estados e processos mentais, até mesmo o pensamento consciente, (incluso aí o aspecto de unidade, de duração e estabilidade, tão importante para para a consciência e para seu eu) realizam-se como propriamente emergentes e efeitos de múltiplas e altamente complexas interações das várias partes do sistema como um todo, uma vez que é isso que possibilita a organização
} 
Nietzsche pensa aqui de maneira holística ${ }^{17}$, na medida em que, para ele, cada um dos conteúdos da consciência são epifenômenos e determinados por uma conjunção psico-física integral, pensada aqui de modo antagonístico. Ele compreende a relação entre impulsos e consciência como tecido agonístico, isto é, como luta de diferentes interpretações interagentes, nas quais "a medida de poder determina à qual ser pertence esta ou aquela medida de poder" (Anotação póstuma 1888, KSA 13, 14[93]). Isso significa que, em luta, os impulsos se constituem e se posicionam tão só de modo determinado. Toda determinação é com isso provisória e depende de fortes relações de força dentro de uma situação geral. Se, por exemplo, pensamentos se põem de acordo uns com os outros, isso acontece não em virtude de uma lógica interna a tais pensamentos, mas, na verdade, sua consecução é imprevisível. "O pensamento seguinte é um signo disto, a saber, de como a situação de poder como um todo se deslocou nesse ínterim" (Anotação póstuma 1886, KSA 12, 1[61]). ${ }^{18}$

A consciência é entendida por
Nietzsche de modo estritamente relacional e funcional, ela é "propriamente apenas uma rede de ligações entre homens" (A gaia ciência 54). Ela é, assim, "não a guia, mas sim um órgão que guia " (Anotação póstuma 1887/1888, KSA 13, 11[145], p. 67).19 Isso significa, no entanto, que eventos físicos não podem ser descritos nem por esquemas tradicionais de explicação, pois não se permite mais ordenar um motivo determinado ou isolado de uma ação como causa, nem mesmo pode ser levado em conta um conceito formal, que, de acordo com o ideal clássico, assenta-se na coerência interna, na unidade harmônica da forma e do conteúdo ou na dominância da forma sobre o material. Justamente isso é pressuposto, como regra, em éticas fundadas esteticamente.

A fim de se preservar contra mal-entendidos, a metáfora da autoridade soberana [Herrschermetaphorik] em Nietzsche, relativamente às representações do comandar-a-si-próprio e da autolegislação, poderia ser, em virtude do que foi apresentado, considerada de modo mais preciso: $\mathrm{Ni}^{-}$ etzsche julga na verdade que nós

\footnotetext{
e garante sua funcionalidade".

${ }^{18} \mathrm{Cf}$. sobre isso STEGMAIER, W. “"Denken”. Interpretationen des Denkens in der Philosophie der Moderne”. in: ANGEHRN, Emil, BAERTSCHI, Bernard. (org.) Studie Philosophica 57, 1998, pp. 209-228, aqui p. 224 ss.; ZITKO, Hans Nietzsches Philosophie als Logik der Ambivalenz. Würzburg: 1991, p. 72 ss. e p. 202 ss.

${ }^{19}$ Cf. Anotação póstuma 1887/1888, KSA 13, 11[145], p. 67 s. Idem, KSA 13, 11[120].
} 
obtemos, partindo do corpo, "a correta representação do tipo de nossa unidade enquanto sujeito, a saber, como regentes no topo de uma comunidade (Anotação póstuma 1885, KSA 11, 40[32], p. 638 s.). O "regente" - a consciência - não deveria ter ciência, como dito, de tudo o que acontece em seu domínio, pelo contrário: "certa insciência [Unwissenheit], pela qual o regente considera algumas obrigações e os distúrbios da comunidade, pertence justo às condições sob as quais se pode reger" (ibidem). Isso não significa, todavia, como alguns gostam de supor a fim de poder abraçar a representação tradicional de sujeito, que a autoridade soberana não teria preocupações com detalhes, regendo assim soberanamente em grande estilo. 20 Isso pode até lhe [a Nietzsche] parecer, mas é um engano. Pois tais unidades nada lhe garantiria, na verdade, iriam informálo de modo falso. Isso aconteceu, segundo Nietzsche, porque o intelecto, "como multiplicidade e aristocracia regente, apenas é capaz de captar uma seleção de vivências, que são mui simplificadoras, tornadas suprassensíveis e inteligíveis, portanto, [nada mais que] falsas vivências, - e com isso avançaria nessas simplificações e nesse tornar-suprassensível, preparando o que hoje se chama comumente "uma vontade"”" (Apontamento póstumo 1885, KSA 11, 37[4], p. 578). Por trás da suposta soberania esconde-se, com isso, "a dependência desses regentes em relação aos regidos e às condições de ranqueamento e divisão de trabalho como meios que possibilitam tanto o individual quanto o todo" (Apontamento póstumo 1995, KSA 11, 40[21], p. 638). A autoridade soberana é apenas um joguete na interação entre impulsos, no melhor dos casos, um ator coadjuvante: "O mais importante é porém: que nós compreendamos o dominante e seus súditos como se fossem do mesmo tipo, todos sentindo, querendo, pensando" (ibidem, p. 639). Segundo Nietzsche, não se deve mais entender a consciência como hierarquicamente sobreposta, mas sim como parte entre outras no interior de uma organização corpórea e como obediente "instrumento" dos impulsos, o qual, na formação de um querer, consegue realizar apenas desejos difusos (cf. Anotação póstuma junho/julho 1885, KSA 11, 37[4], p. 576 ss.).

\footnotetext{
${ }^{20}$ Cf. SCHIPPERGES, Heinrich: Am Leitfaden des Leibes. Zur Anthropologik und Therapeutik Friedrich Nietzsches. Stuttgart: 1975, pp. 69-73. Cético em relação à extensão dessa figura da autoridade soberana é: SCHLIMGEN, E. Nietzsches Theorie des Bewußtseins, pp.. 61-69.
} 
O termo de Nietzsche para a instância de domínio [Herrschaftsinstanz] mais abrangente em relação à consciência é o "si-próprio" [Selbst]. Também esse conceito enseja mal-entendidos, quando é compreendido à maneira tradicional, isto é, como pessoal.21 Em Assim falou Zaratustra, ele é designado da seguinte maneira: "Que vosso si-próprio [euer Selbst] seja presente em ações assim como a mãe o é para com o filho: seja essa para mim vossa palavra para virtude!" (Assim falou Zaratustra II, Dos virtuosos), o que pode ser entendido como exigência de se assenhorear das virtudes próprias e com isso se determinar. Antes já havia ficado claro o seguinte: "Ferramenta e brinquedo são o sentido e o espírito: atrás deles está ainda o si-próprio. $\mathrm{O}$ sipróprio mira ainda com os olhos dos sentidos, ele escuta também com os ouvidos do espírito. O sipróprio sempre ouve e mira: ele compara, subjuga, conquista, destrói. Ele domina [herrscht] e é também quem domina o eu [des Ich's Beherrscher]. Por trás de seus pensamentos e sentimentos, meu irmão, encontra-se um poderoso senhor, um desconhecido sábio ele se chama si-próprio. Em teu corpo ele habita, ele é o teu corpo [...]. Teu si-próprio ri de teu eu e de seus orgulhosos rompantes. "O que são para mim rompantes e devaneios do pensamento? diz para si. Um atalho para meu desfecho. Eu sou as andadeiras do eu e o insuflador de seus conceitos"'” (Assim falou Zaratustra I, Dos desprezadores do corpo).

Os conceitos si-próprio e consciência são separados um do outro. $\mathrm{O}$ si-próprio está privado de ter domínio da consciência e do eu, e se ele chega a se assenhorar, o faz de um modo completamente impenetrável para ambos. ${ }^{22}$ Com isso, não se pode estabelecer qualquer relação evidente entre o si-próprio e a consciência, nem mesmo, consequentemente, estabelecer uma unidade ética e individual entre o si-próprio e a ação. Nas palavras de Zaratustra: "Uma coisa é o pensamento, outra, o ato [de pensar], outra ainda a representação desse ato. O círculo causal não os circunda" (Assim falou Zaratustra I, Do pálido criminoso).

\footnotetext{
${ }^{21}$ Cf. GERHARDT, V. Selbstbegrüdung, p. 42.

${ }^{22}$ Gerhardt, contrariamente, julga que poder-se-ia conceber em Nietzsche um movimento em direção oposta. Por um lado, ter-se-ia a razão como instrumento do corpo, por outro, no entanto, o inverso, quer dizer, o corpo como instrumento da razão, a qual poderia dispor [do] e dominar, de quando em quando, o corpo. A última posição não seria possível seguir. A meu ver, não há para esta última afirmação nenhuma evidência textual satisfatória. Além disso, estar-se-ia contrariando as intenções de Nietzsche, quando se busca arretar a possibilidade, que é transitória e dependente de uma perspectiva falsa, de um domínio da razão com um argumento transcendental irredutível. Cf. GERHARDT, V. "Die grosse Vernunft des Leibes: Ein Versuch über Zarathustras Nietzsches vierte Rede". in: do mesmo autor, Nietzsches ,Also sprach Zarathustra'. Berlin: 2000, pp. 123-164, em especial p. 128 ss. e. p. 133.
} 
Com isso se coloca a questão: como o si-próprio pode ser compreendido? E aqui entra em jogo a arte.

\section{Formas da arte, formas da vida}

Nietzsche oferece diferentes maneiras de se conceitualizar o sipróprio. Pode-se eleger, em primeiro lugar, a "lógica de nosso pensar consciente" como modelo. Ela seria, todavia, "apenas uma forma tosca e simplificada daquele pensamento do qual nosso organismo, sim, cada órgão do mesmo, tem necessidade" (Anotação póstuma 1885, KSA 11, 34[124]). Poderse-ia tentar descrever a diversidade complexa dos modos ativos de viver como algo não conforme a uma necessidade prática vital, mas sim a uma maneira estética: "Um pensar-concomitante [Zugleich-Denken], por exemplo, é necessário, [mas] dele temos vaga ideia. Talvez um artista da linguagem: recalcular o peso e a leveza das sílabas, o antecipar, ao mesmo tempo em que se busca por analogias para a gravidade do pensamento com as capacidades fonéticas e fisiológicas da laringe, isso ocorre concomitantemente, mas claramente não se tem consciência" (ibidem). Como expressão de uma atividade a lógica é adequada; como modelo de conhecimento, no entanto, as essenciais concepções da arte, mais amplas e elásticas, se sobressaem.

Isso tem uma interessante consequência: a unidade flexível da obra de arte pode servir como modelo de conhecimento para os modos ativos de viver 23 , de modo algum, porém, como modelo ético. 24 O subsolo caótico é conhecido, aceito e representado pela arte, jamais dominado. $\mathrm{O}$ conceito de unidade da obra de arte é totalmente diverso daquele da lógica, da ética e também da clássica psicologia da arte. Devese se cuidar para não compreendêlo unilateralmente sob o signo do apolíneo e, segundo essa perspectiva, considerar o caos como seu antípoda passivo e sem-forma, no qual intervém uma atividade ca-

\footnotetext{
${ }^{23}$ Recorrendo a Nietzsche, as possibilidades de uma interpretação "estética" dos processos psíquicos são mostrados de modo lúcido em: LOCH, Wolfgang. Deutungs-Kunst. Dekonstruktion und Neuanfang im psychoanalytischen Prozess. Tübingen: 1993.

${ }^{24} \mathrm{E}$, vice-versa, a lógica pode servir como exemplo de uma atividade, porquanto ela produz simplificações fictícias, mas não como modelo de conhecimento.

${ }^{25}$ Tais representações são tematicamente ubíquas na literatura. Cf. Especialmente o capítulo "Nietzsches Apollinik" na obra de Schmid: Auf der Suche nach einer neuen Lebenskunst, p. 181 ss., e do mesmo autor: Das Dasein — Ein Kunstwerk. Os pressupostos da interpretação de Schmid são, nesses textos e passagens, brevemente recapitulados: Ele afirma que Nietzsche teria em vista uma inversão, concebida segundo três pilares, do conceito de sujeito: "1) O sujeito não é mais, como seu conceito sugere, uma espécie de súdito, que se submete a um poder objetivo, mas sim ele cuida de reger a si mesmo, para, a partir desta nova posição de poder, ser capaz de empreender resistência aos poderes subjetivadores. 2) O sujeito constitui-se não somente no pensar, ele não é mais exclusivamente
} 
paz de dar forma, como que organizando e harmonizando.25

Mais tarde, com a modernidade estética, a relevância do par conceitual forma e matéria foi questionada, e a forma foi explicada com relação à "coisa mesma". Ao mesmo tempo, as representações segundo as quais tudo pode ser forma foram, com isso, ampliadas, e não menos importante foi o fato de que aquilo que outrora se designava como caos passou a ser reconhecido também como uma forma possível. A unidade de uma obra de arte em geral não pode ser criada simplesmente por meio de sua estrutura externa, mas sim em virtude de princípios de sua organização, em virtude de seus procedimentos estéticos. A unidade estética criada por meio da interação desses procedimentos não assenta-se, de modo ingênuo, sobre a forma da obra [Gestalt des Werkes].26 E ela também não pode ser comparada com modalidades de unidade da vida fática.

\section{Estilo e estilos}

Os apologistas dessa perspectiva, segundo a qual Nietzsche pretenderia ensinar uma nova forma da arte de viver, parecem reivindicar passagens como esta: "nós, porém, queremos ser os poetas de nossas vidas, antes de tudo, nos mínimos detalhes e no que há de mais cotidiano" (A gaia ciência 299), ou em outra, ainda mais usada:

\section{Uma coisa é necessária - "dar estilo" ao seu caráter — uma grande e rara arte!}

\footnotetext{
sujeito-cogito, mas sim encontra-se na intersecção entre pensamento e existência, entre práxis e reflexão sobre a práxis, para com isso estar aberto à transformação. 3) O sujeito não se compreende mais como elemento fundador e substancial, como o que é mais próprio, autêntico, como algo a ele profundo e abscondido, desconhecido de si próprio, mas sempre lá, dormitando. Ele se compreende antes como algo capaz de se produzir e de se dar uma forma. [...] O estado dionisíaco não é aí fim em si mesmo, mas, sobretudo, estado do que é sem-forma [Zustand der Formlosigkeit], que evoca o trabalho na forma e no qual qualquer forma sólida há de ser despedaçada" (ibidem, p. 654). Independente de uma idiossincrática história do conceito, que aqui remanesce em sua interpretação do sujeito, pode-se, em primeiro lugar, observar que a leitura de Schmid contradiz as passagens acima citadas do texto. Aquele que dá forma à sua própria vida [der Gestalter seines Lebens], que Schmid faz equivaler, ciente do contexto histórico, com a concepção de artista, toma a vida não simplesmente como material em seu obrar. A segunda suposição de Schmid deixa em aberto o que ela deveria explicar, a saber, como uma tal "intersecção entre pensamento e existência" pode se realizar, e seu terceiro ponto de vista é, em si, contraditório: como é possível um sujeito, que deve ser criado, poder compreender antecipadamente a si próprio como aquele que é capaz de criar? Do mesmo modo é questionável, como acima já foi explicado, o conceito da forma apolínea que Schmid unilateralmente introduz com seu concept-art-model. Afinal, Schmid pensa a forma não como algo fechado (ibidem), em oposição novamente a Früchtl, que elucida assim a expressão "forma de vida” [Lebensform]: “"Forma” é conceito contrário e complementar ao caótico, ao indomado, ao amorfo, ele se deixa ser usado como sinômino de "unidade" e "ordem" e, nesse sentido, lembra aquele par conceitual advindo da teoria do conhecimento, qual seja, forma e matéria" FRÜCHTL, Ästhetische Erfahrung und moralisches Urteil, p. 170.

${ }^{26}$ Sobre o conceito de forma na modernidade estética, ver BÜRGER, Peter Prosa der Moderne. Frankfurt am Main, 1992, pp. 13-59; ECO, Umberto. Das offene Kunstwerk. Frankfurt am main: 1993; SCHEER, Brigitte. "Zeichenbildung und Zeichenverstehen am Beispiel der Malerei". in: SIMON, Josef (org.). Orientierung in Zeichen. Frankfurt am Main: 1997, pp. 197-205.
} 
Ela é praticada por quem vislumbra tudo que sua natureza dispõe de forças e fraquezas, e então inclui isso a um plano artístico até que cada uma apareça como arte e razão, de modo que também as fraquezas encantem os olhos. [...] - Há de existir naturezas fortes, dominadoras, que apreciem sua mais sutil felicidade na coação, na constrição e no se sentir completo sob lei própria; [...] Inversamente, são os caracteres fracos, impotentes de seus próprios caracteres, que odeiam a constrição do estilo: eles sentem que, se essa furiosa coação lhes fosse imposta, teriam que se tornar reles mortais sob ela: - eles se tornam escravos, tão logo passam a servir, eles odeiam servir. Tais espíritos - podem ser espíritos de primeira ordem - estão sempre procurando dar forma e interpretar a si mesmos e ao seu entorno como natureza livre - selvagem, arbitrária, fantástica, caó- tica, surpreendente: estão ansiosos por fazer isso, porque só assim julgam fazer-lhes bem. Pois uma coisa é necessária [Eins ist Noth]: que o homem alcance sua satisfação consigo mesmo - seja por essa ou aqueloutra criação literária [Dichtung] e arte: apenas assim pode o homem olhar-se de modo suportável! Quem consigo é insatisfeito, está continuamente pronto para retaliar a si mesmo por isso: nós outros seremos suas vítimas, e isso por que teremos sempre que suportar seu olhar de ódio. Pois o olhar do feio torna ruim e sombrio. (A gaia ciência, 290) 27

Também essa passagem não é unívoca, como sugerem os seus intérpretes. Quando Schmidt assim a entende: "O ideal de Nietzsche é aquele da individualidade estilizada"28, ele só pode afirmar isso porque se reporta exclusivamente à primeira parte do aforismo, cujo assunto ali é a natureza forte, desviando-se porém da segunda parte. Naturalmente, ele

\footnotetext{
${ }^{27}$ Sobre isso ver REUBER, R. Ästhetische Lebensformen; FRÜCHTL, Ästhetische Erfahrung, p. 159 ss.; SCHMID, Auf der Suche nach einer neuen Lebenskunst, p. 190 ss.

${ }^{28}$ SCHMID, Das Dasein — ein Kunstwerk..., p. 57.
} 
interrelaciona a figura artística de Zaratustra com esta do indivíduo forte. Eis aí "o plenamente artístico si-próprio de uma nova arte de viver, a suprema instância da afirmação".29

Manifestamente, a "satisfação consigo" e a força para suportar que cada olhar possui, ambas, de longe, são (justo para "espíritos de primeiro ordem"!) pretextos sem visos, poder-se-ia dizer que são [pretextos] resignados com relação ao ato estético de darse-a-si-mesmo-uma-forma. 30 No que concerne ao suposto papel de herói de Zaratustra, correlato à estética da autoafirmação na obra homônima, há grande dúvida se Nietzsche "com satisfação" alcança, algures, a personagemZaratustra via tentativas de criação, pois estas fracassam frequentemente.31

Esse ponto diz respeito também à imagem de Goethe para Nietzsche. O modelo de Goethe, que para muitos intérpretes deve ser visto como positivo exemplo para o programa de sua arte de viver, não é de modo algum claro como comumente se supõe. ${ }^{32}$ Goethe é denominado por Nietzsche como um dos raros exemplos para uma bem sucedida autocriação [Selbsterschaffung]: "O que ele queria era a totalidade;[...] ele se disciplinava pela completude, ele se criou" (Crepúsculo dos ídolos, Sentenças de um extemporâneo, 49). Isso tem, segundo Nietzsche, razões específicas. No aforismo Sobre a revolução na poesia (Humano, demasiado humano I, 221), ele havia argumentado da seguinte maneira: na evolução da poesia moderna na Alemanha, ocorreu uma forte rejeição da forma e um salto de volta ao naturalismo. Nessa situação, Goethe tentou se salvar, "porquanto ele sabia renovadamente e de diferentes modos se comprometer". Mas Goethe não teria se valido muito disso. Pois, "se o fio da evolução [da poesia] outrora se rompeu", essa [evolução] só poderia ser de novo possível [se conduzida] pelo mais talentoso e isso na direção de "uma experimentação contínua. [...] Por

\footnotetext{
${ }^{29}$ Ibidem, p. 61.

${ }^{30}$ Pelo que me é conhecido, apenas Thomä observou que a segunda parte desse aforismo postula a "satisfação consigo" e não mais a estilização do caráter como emergente tarefa. THOMÄ, Erzähle dich selbst..., p. 153.

${ }^{31}$ Sobre isso, cf. ZITTEL, Claus. Das ästhetische Kalkül von Friedrich Nietzsches "Also sprach Zarathustra". Würzbug, 2000; STEGMAIER, Werner. "Anti-Lehren. Szene und Lehre in Nietzsches Also sprach Zarathustra. in: GERHARDT, V. Nietzsches "Also sprach Zarathustra, pp. 191-224. Sobre problemas fundamentais de novos projetos que se seguem a Nietzsche, ver: ZITTEL, Claus. Selbstaufhebungsfiguren bei Nietzsche. Würzburg, 1995.

${ }^{32}$ Cf., por exemplo, NEHAMAS, A. Nietzsche..., p. 242 e p. 260; FRÜCHTL, Ästhetische Erfahrung und moralisches Urteil, p. 170; GERHARDT, V. "Nietzsche, Goethe und die Humanität". in: RESCHKE, Renate (org.). Zeitenwende - Wertewende. Berlin, 2001, pp. 19-30. Contrariamente, ver meu verbete: Goethe. in: OTTMANN, Henning. Nietzsche-Handbuch. Stuttgart, 2000, p. 385 ss.
} 
quanto tempo ainda, porém? A irrupção de uma torrente de poesias de todos os estilos, de todos os povos, tem que gradualmente banhar todo o solo sobre o qual um silencioso e abscondido florescimento seja ainda possível; todos os poetas tem que se tornar imitadores experimentalistas [experimentierende Nachahmer], copistas atrevidos, a força deles, de início, pode ser ainda muito grande" (Humano, demasiado humano I, 221). Mesmo Goethe, como julga Nietzsche, conseguiu isso apenas quando, em meio aos fragmentos herdados da tradição, "compôs em versos [andichten], com a fantasia do olhar, a antiga perfeição [Vollkommenheit] e completude [Ganzheit], quando a força do braço se mostrava muito fraca para construir justo ali onde poderes colossais já clamavam destruição. Assim viveu na arte tal como na memória da verdadeira arte: seu poetizar [Dichten] tornou-se expediente da memória" (Humano, demasiado humano I, 221). Um tal arte nada mais cria de novo: "Não indivíduos, mas sim mais ou menos máscaras ideais; nenhuma realidade, mas sim um todo alegórico; caracteres do tempo, cores locais tornadas evaporadas e míticas até quase a invisibilidade; [...] tornadas sem efeito em todos os sentidos exceto no artístico; sem conteúdos novos ou caracteres, mas tão só os antigos, aqueles que há muito habitam continuamente um estado de ânimo que se renova e que se remodela [Neubeseelung und Umbildung]" (ibidem). ideal do dar-se-a-si-mesmo-umaforma deixa-se, na modernidade, apenas rememorar, uma existência estética existe, tal é o implacável recado de Nietzsche, apenas na fantasia.

\section{O perspectivismo estético e o in- divíduo soberano}

Um outro caminho partindo da estética para a ética, e desta de volta para aquela, é aquele pavimentado pelo perspectivismo de $\mathrm{Ni}$ etzsche. ${ }^{33}$ Aqui são eleitas como ponto de partida as possibilidades de uma autoconstituição livre, autônoma. Pode-se aqui distinguir pelo menos duas variantes principais. Uma primeira destaca as possibilidades positivas, associadas ao perspectivismo, de um indivíduo soberano e procura mostrar que aí elementos normativos estão envolvidos, bem como que é

\footnotetext{
${ }^{33}$ Sobre o perspectivismo de Nietzsche, ver meu artigo: Perspectivismus. in: OTTMANN, H. (org.) NietzscheHandbuch., bem como o capítulo "ästhetische Perspektivismus" em ZITTEL, Claus. Das ästhetische Kalkül Nietzsches "Also Sprach Zarathustra", p. 99 ss.
} 
pressuposto pela escolha de perspectivas um ponto de vista desde sempre transcendental e universalista. A segunda variante interpretativa, ao contrário, acentua a valência ética justo do modo de ver [der Einsicht] como estando presente na relatividade de cada ponto de vista perspectivo.

A interpretação de Nietzsche concebida por Friedrich Kaulbach exemplifica o ponto de partida da primeira variante. Sua abordagem é destacável pela confiabilidade e método, e isso em diversos aspectos (justo para um tratamento, pífio na pesquisa Nietzsche, de Assim falou Zaratustra). Ele reivindica explicitamente levar em conta a forma estética da obra de Nietzsche. Uma vez que Kaulbach em seu livro sobre a filosofia experimental de Nietzsche retrabalhou, com clareza, o significado das riquezas da perspectiva, ${ }^{34}$ começa a hierarquizá-las (de modo anestético), ao mesmo tempo em que interpreta, imediatamente, a metáfora da ascensão/subida [Aufstiegsmetaphorik] em Assim falou Zaratustra, atribuindo-lhe uma teleologia interna: quanto mais alto o ponto de vista e quanto mais vasta a visão, segundo Kaulbach, tanto mais forte e soberano é o "espírito livre" em seu poderdispor de múltiplas perspectivas de mundo:

Em seu movimento de subida [Aufwärtsgang], ele alcança pontos de vista que lhe abrem perspectivas, e estas são superiores àquelas que ele conseguira acessar até então. Nas novas perspectivas, seus anteriores companheiros vão se tornando desconhecidos, pois influências atuantes sobre ele afetam sua consciência. Ele alcança pontos de vista cada vez mais altos, mais soberanos, até que ele, por fim, alcança a meta da história do pensamento filosófico: em um tal patamar que o permita ver as coisas em si mesmas, sem-véu e sem máscara. No Zaratustra, encontramos o discurso da subida [Aufstieg] na montanha das perspectivas superiores, do ir-além-desi e do conquistar mais altos e soberanos pontos de vista. A partir desses surge o conhecimento, a crítica, o desmascaramento, a dominação das próprias perspectivas su-

\footnotetext{
${ }^{34}$ KAULBACH, F. Nietzsches Idee einer Experimentalphilosophie, p. 59-130, aqui p. 75.
} 
peradas e dos modos de pensar anteriores. Aqui torna-se claro que a história de ascensão [Geschichte des Aufstiegs] deve ser um acontecer gradual, passo a passo, que tem sua consequência interna, sua >lógica<, não podendo ser ignorada impunemente. Trata-se em Nietzsche de acentuar a consistência interna dessa ascensão, por meio da qual garante-se que ele não se perde num anárquico ser, nem num anárquico pensar, mas sim recobre de uma lógica a disciplina segundo a qual cada trans-posição [Über-Gang] e sua dissipação [Loslösung] torna-se sempre uma nova necessidade do ser e do pensar. 35

Esse modo de interpretar não se deixa confirmar no contexto de Assim falou Zaratustra: Zaratustra viaja, por exemplo, para as "ilhas bem-aventuradas", na parte dois, onde ele não consegue conquistar um ponto de vista "superior". Suas andanças posteriores o conduzem, lá na parte quatro, a um contínuo sobe e desce pelas mais diferentes paisagens, junto às quais fica seu destino [ $\mathrm{Zi}$ elpunkt], a saber, sua caverna e a parte que fica à entrada dela. No começo da quarta parte, Zaratustra sobe, a partir da caverna, para o topo de uma montanha (Assim falou Zaratustra "O sacrifício do mel"), o que segundo Kaulbach significa que o discurso sustentado lá de cima marca a posição de sua visão superior. Nietzsche deixa Zaratustra também esclarecer: "aqui em cima posso livremente falar, como diante de cavernas de eremitas" (ibidem). Nesse discurso, porém, apresentase Zaratustra como "o mais maldoso de todos os pescadores de homens". Ele agradece ao seu destino pelo fato de "conceder[lhe] tempo para farsas e maldades: sim, pelo fato de hoje eu ter subido até o topo da montanha para uma pescaria" (ibidem). A subida como farsa [Aufstieg als Posse], os discursos como bufonarias [Possenreissereien], isso tem lá sentido com relação ao desdobramento da ação dramática, ao garantir a pescaria de homens, e esta, culminando na agitação intensa que ocorre na caverna de Zaratustra. Mas mesmo a circunstância na qual Zaratustra não permanece no cume da montanha já contradiz a lógica evolutiva que Kaulbach atribui ao percurso de

${ }^{35}$ Ibidem, p. 79. Consultar também p. 294. 
Zaratustra: o ponto de vista "mais alto" é apenas transitório, em seguida ocorre a descida/descensão [Abstieg] para a região da caverna. Pode-se com isso dizer com mais propriedade que em Assim falou Zaratustra as supostas perspectivas superiores são sempre perdidas, caricaturadas ou mesmo criticadas. A forma estética que denota a riqueza das perspectivas implica as perspectivas particulares em relação dinâmica. Nenhum panorama das perspectivas revela-se de um ponto de vista superior, nem mesmo por um determinado momento, aos olhos de Zaratustra, e assim ninguém seria capaz de compreender todas as óticas segundo uma única visão totalizante. O tableau das perspectivas apresentados pode ser percorrido apenas internamente, isto é, apenas por meio de um duplo ato, compreender e concorrer [Nach- und Mitvollziehen], ambos pertinentes às diferentes mudanças de ponto de vista bem como à experiência do fracasso presente em cada tentativa de fixar e absolutizar um dos pontos de vista alcançados. O perspectivismo estético é muito mais radical do que aquilo que Kaulbach (e também Volker Gerhardt) lhe atribui, ele não se deixa prender a uma suposta "reivindicação de unidade presente no conhecer e agir". ${ }^{36}$ Com relação à riqueza de perspectivas, tornada possível por meio da forma da encenação estética, não se visa à, ou se alcança uma, síntese de perspectivas como se fosse uma ótica abrangente. 37 A perspectiva estética não oferece justo uma base para outras perspectivas. Que Nietzsche, quando ele denomina o perspectivismo como condição de conhecimento, tenha que, ao mesmo tempo, conquistar um meta-ponto-devista, $\sqrt{8}$ unicamente a partir do que ele poderia descrever o limite das perspectivas - isso seria algo totalmente questionável. Para Nietzsche, não há a perspectiva do perspectivismo e por isso jamais se pode encontrar nele a tentativa de uma reobjetivação transcendental-filosófica de seus perspectivismo. Pode-se mudar, trocar, variar perspectivas, porém jamais alcançar um meta-registro delas. Se para Nietzsche o mundo pode ser compreendido como soma das interpretações assumidas a partir de cada uma de suas perspectivas, então cada respectivo ponto de vista encontra seu limite e relativização no conflito

\footnotetext{
${ }^{36}$ Cf. GERHARDT, Volker. Die Perspektive des Perspektivismus. in: Nietzsche-Studien 18, 1989, pp. 260-81, aqui p. 278.

${ }^{37}$ Cf. STEGMAIER, Werner. Philosophie der Fluktuanz. Dilthey und Nietzsche. Göttingen, 1992, p. 56, nota 39.

${ }^{38}$ Ver, contra isso, GERHARDT, op. cit., p. 263 ss.
} 
com outras posições, e isso jamais no sentido de uma autonomia supramoral [im Sinne übersittlicher Autonomie]. Atribuir isso a Nietzsche como sendo seu objetivo é uma posicionamento ideológico. ${ }^{39}$ Esse é caso, quando Gerhardt argumenta, que na "autolegislação do "homem soberano"” o "perspectivismo de Nietzsche [tornarse-ia] prático" e o "indivíduo", enquanto "vivente autorreferente" $\mathrm{e}$ "responsável por si", tornar-se-ia "indivíduo autônomo supramoral" 40 Teríamos um Nietzsche assim tão kantianizado e domesticado eticamente apenas se subestimássemos drasticamente o perspectivismo de Nietzsche.

Mesmo sem ter que assumir esse meta-ponto-de-vista, é ainda assim possível conhecer o limite de uma perspectiva e também, metodicamente, ultrapassálo; isso ocorre quando se muda de perspectiva. Quanto se é capaz de trocar os pontos de vista de uma ponderação, colocandoos em relação uns com os outros, tanto mais rico e complexo o fra- casso em se alcançar um conjunto de imagens criadas de modo poliperspectivístico. Essa imagem de um todo não pode ser mais positivada, não pode ser compreendida, por assim dizer, a partir de uma metaperspectiva ou ser resumida pela soma das perspectivas particulares. Pois, segundo Nietzsche, o "ser" do mundo pode ser concebido apenas segundo relações e esse mundo é "essencialmente, em cada ponto, diverso: o mundo pressiona todos os pontos, e cada ponto resiste a ele - e essa soma é, em cada caso, totalmente incongruente" (Anotação póstuma 1888, KSA 13, 14[93]). Jamais se pode ter, simultaneamente, diante dos olhos, as possibilidades divergentes de relação. Em todo caso, deixa-se antecipar, a partir dos respectivos ângulos do olhar, uma representação do todo, isso, porém, na consciência das modificações ainda esperadas, ainda não conhecidas.

Tal visão é levada em conta, especialmente, por intérpretes de Nietzsche com interesse numa fi-

\footnotetext{
${ }^{39}$ Bem claro fica isso em Recki, que faz uma variação teórico-cultural da posição de Gerhardt, e diferentemente de Gerhardt, no entanto, destaca em Nietzsche o fracasso como dissolução de reivindicações universalistas: "Tudo que é individual está relacionado desde sempre, em seu produtivo ser-íntimo, àquele medium, que é a cultura, capaz de fundar coisas universais” (in: RECKI, B. “Artisten-Metaphysik', p. 265). A partir de reivindicações criadoras Recki deduz, sem delongas, uma "correspondência normativa na autocompreensão" (ibidem, p. 278). No entanto, "o individualismo de Nietzsche [fracassaria] ante uma reivindicação de universalidade", pois levar isso "ao pé da letra" significaria "realizar a passagem para um universalismo moral das reivindicações, para o que uma ética é requerida" (ibidem, p. 284).

${ }^{40}$ Ibidem, p. 275. Cf. os outros supracitados escritos de Gerhardt. Para a crítica deles, ver. HARTMANN, Bettina. Über freie Geister und souveräne Individuen. Ein Beitrag zu Nietzsches Ethik. Dissertação de Mestrado em Filosofia. Freie Universität zu Berlin, 2000.
} 
losofia dos signos, tal como é o caso com Josef Simon, Werner Stegmaier e Brigitte Scheer. Podese recorrer a eles para se pensar uma ética, mas sem violentar com isso os textos de Nietzsche. A filosofia de Nietzsche é interpretada não na linha de uma normatividade universalista, mas é ele um pensador que insiste numa não compensatória diferença do indivíduos:

O critério de verdade não é aqui a proximidade ou distância a um ser impessoal, isto é, o dizer como o ser é [das Sagen, wie es sei], mas sim o poder suportar outras opiniões seja como reivindicação ou o poder suportar crenças alheias no sentido de que é necessário à vida ter que assumir como verdadeira as "coisas" conforme cada limite e perspectiva, até mesmo [poder suportar] um outro uso de conceitos, pelos quais a reivindicação é feita, uma reivindicação que não pode ser determinada de modo normativo como esses conceitos o podem, conceitos que estão certos, "por fim", de suas elucidações em juízos. Depende, antes de mais nada, disto, se é possível ser-entendido. Isso ocorrendo, então, ocorrerá sem o conceito de sua possibilidade, quer dizer, [ocorrerá] esteticamente, e com isso sem se reivindicar ou ter certeza de que se está ancorado no ser. A ilusão do se-por-deacordo [Schein der Übereinstimmung] tem que ser aqui o critério suficiente da verdade. 41

O perspectivismo de Nietzsche conduziria, de acordo com essa

\footnotetext{
${ }^{41}$ SIMON, Josef. "Die Krise des Wahrheitsbegriffs als Krise der Metaphysik. Nietzsches Alethiologie auf dem Hintergrund der Kantischen Kritik". in: Nietzsche-Studien 18 (1989), p. 242-259, aqui p. 257 s. Talvez isso seja, no entanto, uma compreensão temperada mui harmonicamente do assim chamado "entender estético", que pretenderia dissolver as conflituosas discussões com provocações estéticas, as quais podem conduzir para o fracasso dos atuais esforços em busca de entendimento, em um "deleite não-conceitual". Justamente a "ilusão do se-por-deacordo" não é admitida frequentemente pelas obras de arte (vide o caso das refrações ficcionais [Fiktionsbrechung]). Também uma teoria da compreensão [Verstehenstheorie] deontológica, multiperspectivista, tal como ela trafega na concepção ético-estética de Josef Simon, restaria em dificuldades, se ela é confrontada com o perspectivismo estético de Nietzsche, uma vez que ela se baseia em um mínimo necessário da ilusão permanente. Fosse a crença na ilusão destruída, fosse a estabilidade da metáfora diluída, então a compreensão [die Verständigung] não seria obtida e o "efeito-placebo" dos sagrados enganos seria perdido para sempre. Se não mais as capacidades de autoconservação e de compensação da ilusão são atuantes, resta ainda como critério a ascensão da vida, que, depois do abandono justo de pontos seguros, poderia ser encontrada ainda na paixão pela destruição das ficções necessárias à vida, no autossacrifício trágico, bem como no prazer em fazer da própria vida uma obra de arte trágica, ou seja, na felicidade do declínio alcançado por si próprio [Freude über dem gelungenen eigenen Untergang].
} 
compreensão, não para um entender intersubjetivo [zu intersubjektivem Verstehen], mas, em todo caso, para uma orientar "inter-individual" [zu einem "interindividuellem" Orientieren]. ${ }^{42}$ Liberdade é compreendida aqui não como autolegislação autônoma, mas como "liberdade de poder abandonar reivindicações morais reputadas de "justas" em detrimento de outras",43 Certezas de que temos uma posição própria são colocadas radicalmente em questão e no lugar de uma ética, que propaga a ideia de um indivíduo, surgem tanto o saber acerca dos limites e da subjetividade irredutível da própria perspectiva quanto, ao mesmo tempo, a admissão da impotência da própria interpretação, podendo isso tornar-se ético na medida em que outras morais não mais encontram-se centradas nesse fundamento e, além disso, na medida em que são deixadas "incompreensíveis" em seu/sua ser-outro/alteridade [in ihrer Andersheit]. Experiência ética e estética relacionam-se aqui de maneira análoga, uma vez que a nãocompreensão [das Nichverstehen] obstinadamente acompanha justo a experiência estética com a obra de arte e as "catástrofes de sentido e interpretação" 44 existentes nela são significativas eticamente, pois há um fracasso nas tentativas de absolutização e universalização do próprio ponto de vista.

\section{Identidade narrativa}

A crítica à permuta dos conceitos de forma estética e forma ética deve ser concretizada agora em face de concepções ético-estéticas que se tornaram especialmente proeminentes, concepções essas que procuram traduzir a representação estética de uma "identi-

\footnotetext{
${ }^{42}$ Cf. STEGMAIER, Werner. "Philosophieren als Vermeiden einer Lehre. Inter-individuelle Orientierung bei Sokrates und Platon, Nietzsche und Derrida. in: SIMON, Josef (org.). Distanz im Verstehen. Frankfurt am Main, 1995, pp. 213-238.

${ }^{43}$ Ver STEGMAIER, Werner. Nietzsches “Genealogie der Moral”. Darmstadt, 1994, p. 3.

44 "O que ocorre em obras de arte inovadoras são antes catástrofes de sentido e interpretação. O colapso das atuais interpretações de mundo não representadas e experimentadas sem que a segurança de um novo ponto de vista seja alcançado". in: SCHEER, B. "Zum Verhältnis von Zeichen und Erfahrung. Anmerkung zu Josef Simons Konzeption einer >Philosophie des Zeichens $\prec$ in: HOFFMANN, Thomas Sören e MAJESTSCHAK, Stephan (org.). Denken der Individualität. Festschrift für Josef Simon. Berlin, 1995, p. 359-365, aqui p. 364. Cf. também da mesma autora: "Zeichenbildung und Zeichenverstehen am Beispiel der Malerei", acima citado. B. Scheer corrige com essa exposição da experiência negativa do fracasso em face de uma obra de arte a acima introduzida leitura harmonizadora de Simon. Em um novo artigo, Scheer aproxima-se, no entanto, de posições que sustentam uma ética da soberania (o já citado artigo de Scheer "Das Verhältnis von Ästhetik und Ethik im Denken Nietzsches"). Lá o impulso subversivo e crítico à metafísica é retrabalhado por ela (ver p. 52). Em face dos critérios para "se ter êxito ético" e para se sentir "responsável por coisas avaliadas esteticamente" (p. 61), Scheer aponta para uma penetrabilidade entre esferas de valor ético e estético, que seria viabilizada via categorias do estilo e gosto, essas capazes de colapsarem qualquer tipo de disciplina. Em seguida, não mais é destacado o aspecto subversivo e dissolúvel da arte, mas sim a restrição do estilo como pano de fundo, e então é feita uma associação com a posição de Gerhardt.
} 
dade narrativa" para um registro ético. Um tal programa é representado por exemplo por Martha Nussbaum e Alaisdair MacIntyre. Destaca-se também aqui um ceticismo quanto a éticas orientadas universalmente, e favorecida é, ao invés disso, uma ética do indivíduo aos moldes da aristotélica. Partindo da representação segundo a qual a percepção estética possibilita uma mais rica e mais intensa percepção da realidade, assume-se que ela deve ser também relevante do ponto de vista prático, argumenta Nussbaum, na medida em que, com tal percepção, cada uma das margens de manobra das ações individuais pode ser melhor explorada e a individualidade de seus protagonistas compreendida de modo mais preciso.

Já as premissas do argumento de Nussbaum não são convincentes. Apesar de se admitir, tranquilamente, que ao indivíduo é aberta uma mais rica e distinta percepção da realidade via expe- riência com obras de arte, esse privilégio parece ter, do ponto de vista ético, certa conotação neutra. Poder-se-ia utilizá-lo também para um crime. 45

MacIntyre associa-se, por sua vez, a uma ética da virtude de matriz aristotélica, na qual narrar a própria vida é algo que se deixa esclarecer como uma virtude própria. Aqui trata-se de alcançar "um conceito de si-próprio [Selbst], cuja unidade repousa na unidade da narrativa".46 A narrativa de uma vida autêntica caracteriza-se por meio de uma coerência, integridade e "compreensibilidade" perfeitas, ela carece de um início, um claro desdobramento e um fim. A vida deve ser conduzida em sequência e isso de tal forma que só assim ela pode ser narrada. Também Nussbaum associa tal ordem narrativa àquela da vida. A vida bem vivida teria então o caráter de uma obra de arte, ${ }^{47}$ e essa relação não valeria apenas como mera analogia. ${ }^{48}$

Como uma forma não é igual

\footnotetext{
${ }^{45}$ Remeto aqui à obra de Thomas De Quincey On murder considered as one of the fine arts de 1827. Significativas, as exaltações de Nietzsche ao "grande criminoso" (por exemplo, no Crepúsculo dos ídolos, Sentenças de um extemporâneo 45) são ignoradas em detrimento daquelas que louvam o indivíduo soberano.

${ }^{46}$ MACINTYRE, A. Der Verlust der Tugend, p. 275 e 292.

${ }^{47}$ Cf. NUSSBAUM, M. Love's knowledge. Essays on philosophy and literature. Oxford, 1990, p. 148 e 162.

${ }^{48}$ Uma posição semelhante pode ser formulada também sem recurso à arte, por exemplo, em: KAMBARTEL, Friedrich. Philosophie der humanen Welt. Frankfurt am Main, 1989. Kambartel fala em "autorrealização", que não segue quaisquer fins determinados, mas que depende de uma forma presente nela, na qual "a vida alcança totalmente seus conteúdos" (ibidem, p. 21). "Nossa vida pode ser aí compreendida como a síntese global de nossas ações e atividades. O discurso da autorrealização considera não uma parte determinada dessa síntese, mas o modo como nós alcançamos nossas ações em seu todo" (ibidem, p. 22). Kambartel cunha assim o conceito de "forma de vida [Lebensform]" ou aquele da "gramática da vida" (ibidem, p. 45), os quais permeiam "todas nossas situações de vida e relações" (ibidem, p. 47).
} 
a outra, assim também uma narrativa não o é em relação a outra. Por exemplo, uma autobiografia pode ser escrita sem qualquer apelo estético e por essa mesma razão emprestar à vida uma "forma" especialmente coerente. Tem-se assim que se diferenciar um conceito vago de estética, sob o qual recai todas as formas de narrativa, e um conceito específico de arte. Uma narração especificamente estética pode proceder com certa liberdade. Ela pode operar com rupturas flagrantes, com mudanças contínuas de perspectivas e incoerências evidentes, e isso é um diferencial no todo. Em textos estéticos, ao contrário de tratados morais, podem ser exaltadas ou despontenciali- zadas certas pretensões de validade [Geltungsansprüche], sem que com isso se rompa com a arte. Para a ética isso seria fatal. mesmo vale para sua autoconstituição, que, sendo coerente esteticamente, encarcera seu sujeito. 49

Por isso não é mera coincidência que, para tais filósofos e filósofas, ávidas(os) por um modelo estético para suas éticas, só é suficiente a circunstância na qual a forma que representa unidade seja proposta de modo autorreferente, a fim de, com isso, falar daquilo que dá moldagem artística [von künstlerischen Formung $\mathrm{zu}$ sprechen]. A isso corresponde um seletivo ponto de vista sobre a arte. Significativamente, não se recorre à escolha de exemplos

\footnotetext{
${ }^{49} \mathrm{O}$ contraprojeto de Rorty, segundo o qual de uma autodescrição narrativa nenhum força vinculada partiria, também subestima o tema, uma vez que ele se permite alcançar a identificação harmoniosa da forma estética e da narrativa da vida de modo trivial. Fracasso pode haver para um autor em sua própria vida, quando ele assume as descrições que um terceiro fez sobre ele. Pois isso não seria original, e nessa medida tais descrições apenas teriam, dito esteticamente, pouca relevância qualitativa. Ao invés disso a livre autocriação enquanto invenção de uma nova linguagem deve gerar algum tipo de certeza para seu criador-artista (o poeta), de que sua vida foi tornada perfeita, pois "a última palavra de seu derradeiro vocabulário é sempre a sua" (RORTY, R. Kontingez, Ironie, Solidarität, p. 164). O critério de originalidade, no qual Rorty insiste para se decidir se o autêntico si-próprio é encontrado ou corretamente estimado em sua contingência, tornou-se, enquanto critério estético muito particular, obsoleto e questionável, do mesmo modo que os critérios classicistas de Nussbaum e MacIntyre. De modo irônico, conceitos de norma, conservadores e atrelados a uma noção de formação tipicamente burguesa, tais como autonomia da obra, autenticidade e originalidade da narrativa romanesca da própria vida, são levados em conta por Rorty. A complexidade intertextual de qualquer narrativa que se relaciona com outros textos (excelente exemplo é Assim falou Zaratustra), quer dizer, a "abertura" da obra de arte ante outras obras e mídias, que por boas razões se encontra no centro das modernas análises da teoria literária, permite-nos dispensar a posição de Rorty. Nietzsche é tomado como exemplo disto, a saber, de que ele releva sua própria posição uma vez que ele não aceitaria, por fim, a própria contingência, esforçando-se por um meta-ponto-de-vista: "Nietzsche, o perspectivista, tem interesse nisto, em encontrar uma perspectiva sob a qual ele, de volta, possa enxergar a perspectiva antes assumida, a fim de assim identificar um padrão" (ibidem, p. 178). Não espanta o fato de que Rorty extrai daqui outra conclusão que não aquela de Gerhardt. Não o indivíduo supramoral, mas sim o além-do-homem, surgindo a partir de uma autocriação, é o que ambicionava Nietzsche (ibidem). Também para Nehamas, em quem Rorty se embasa, objeções semelhantes podem ser feitas. Em Nehamas aparece o antiquado critério da coerência estrita, que se realiza apenas em um texto literário perfeito, critério que deve estar fundido ao ideal da narrativa da vida autêntica. Coerência aqui significa a necessidade absoluta de que cada frase particular esteja amarrada peremptoriamente ao todo da narrativa. Nehamas não destaca a contingência da invenção, mas sim a sua inevitabilidade. (NEHAMAS, A. Nietzsche. Life as literature, p. 200 ss e p. 207 ss.). Sobre isso, ver THOMÄ, Erzähle dich selbst. p. 146.
} 
tal como The sound and the fury de Faulkner, mas adere-se a obras preferencialmente da antiguidade clássica ou do romance realista. MacIntyre favorece Jane Austen e censura explicitamente os contos de Kafka, cujos romances ele rejeita como sendo incompreensíveis; $\sqrt[50]{ }$ já os romances de Henry James, para nos valer aqui de Nussbaum como modelo de um comportamento ético, deveriam ser previamente purificados de seu abismo imoral.

No geral, para todos esses filósofos vale a ideia de que eles podem reduzir uma narrativa a uma "coerência linear", dispensandose de responder, fundamental- mente, por que eles falam de obras de arte como modelos. Para seus fins, basta tomar como padrão o estabelecimento de unidade de algo como uma simples biografia de político, quer dizer, tomar uma narrativa sem qualquer valor artístico. Quando se fala de modo persistente e grandiloquente sobre a arte, freqüentemente acontece isto de se valer de um conceito de arte manifestamente limitado, um que somente é adequado para ser exportado para a ética. ${ }^{51}$ De modo consequente, teóricos de uma ética da vida-como-arte, se eles pintam as obras de arte como modelos éticos, semelhante ao que faz Platão na República, devem

\footnotetext{
${ }^{50}$ Cf. MACYNTIRE, A. Der Verlust der Tugend, p. 285.

${ }^{51}$ De modo surpreendente, pelo menos no que tange a uma rejeição geral de uma ordem superior da narrativa de autodescrição e às consequências antiéticas que surgem daí, Nietzsche se aproxima de posições naturalistas contemporâneas dentro das ciências da cognição, embora a refração autoirônica se distancie por completo destas, no mais das vezes. Isso porque em filósofos crentes da ciência e descrentes da arte, tal como Daniel Dennett, antes é comum se deparar com descrições da conexão entre narratividade e psicologia, que correspondem às intuições de Nietzsche de não cambiar activum e passivum, - e que contradizem toda fácil promessa, proposta pelos éticos, de um dar-se-a-si-mesmo-uma-forma. Dennett compara a narrativa da história da nossa vida, intuitivamente, com o tecer de fios: entretanto, "assim como o tecer fios não é algo que está consciente disto, a saber, de pensar como ele tece os fios [...] , assim não pensamos (diferentemente do que narradores profissionais de história) conscientemente quais histórias devemos contar. Nossas narrativas são tecidas, já que, em grande parte, nós não as tecemos; elas nos tecem. A consciência humana e o que é narrado sobre o si-próprio são seus produtos, não sua fonte. Tais fios e feixes de narrativa parecem ter sido alimentados a partir de uma única fonte [...], elas nos seduzem para isto, a saber, aceitar um centro de gravitação unitário". in: DENNETT, Daniel. Philosophie des menschlichen Bewusstseins. Hamburg, 1994, p. 538. Do ponto de vista fenomenológico, essa aceitação seria uma simplificação extremamente supervalorizada. Como consequência dessa teoria produzir-se-ia para o Eu o seguinte: ele "seria uma abstração, que se define por uma miríade de arranjamentos e interpretações (incluindo as autoatribuições e autointerpretações), as quais compuseram a biografia do corpo vivo, cujo centro de gravidade narrativo é o Eu. Como tal, o Eu representa um papel de destaque no curso cognitivo da economia do corpo vivo, que precisa criar, a partir das coisas que estão ao seu redor, modelos mentais, pois dentre esses o modelo do Eu se sobressai”. Ibidem, p. 547. A noção virtual de si-próprio segundo Dennett convém, assim, apenas a uma unidade funcional, que tem que poder mudar continuamente, sendo aí frágil [brüchig] e inconstante [sprunghaft]. O Eu é apenas a parte atraente dos mais diversos modelos, bem como replicador pragmático de unidades culturais (eis os mais famosos memes [die berühmten Meme]). Mesmo que a metáfora das máquinas cruze transversalmente os modelos de corpos pensados organicamente por Nietzsche, mesmo assim o Eu representa a despontecialização da instância da consciência, a qual justifica a comparação. Em relação ao modelo de conhecimento pensado esteticamente por Nietzsche as posições naturalistas são reducionistas. O valor agregado estético nada modifica, em Nietzsche, do impulso principal. A dissolução da forma é pensada e realizada, em Nietzsche, de modo mais consequente, e, além disso, não há nele uma crendice cientificista. Para diferenciações sistemáticas entre posições naturalistas e aquela de Nietzsche, ver: ABEL, G. "Bewusstsein — Sprache - Natur", acima citado.
} 
distinguir boas e más obras de arte e aí passar a professar culto a obras realistas e herméticas.

Correm perigo os esforços de se empregar uma obra de arte, de modo calculado, como modelo formal, um que questione radicalmente a ideia de unidade totalizante - tal como é o significativo caso de Assim falou Zaratustra. Não pretendo aqui novamente ${ }^{52}$ esclarecer como o texto de Assim falou Zaratustra se organiza-se segundo certa concepção de "material", por assim dizer, a partir de baixo, objetivando uma estrutura fluida tal como metáforas se ligam a outras metáforas em virtude de uma aberta interconexão, que sempre de novo tem que afrouxar os modos de acesso subjetivamente fixados. Pode-se pelo menos uma vez tentar aplicar algum determinado tipo de gênero, seja romance, drama, poesia didática [Lehrgedicht], e logo se notará quão difícil é encontrar para a obra uma satisfatória descrição de sua forma literária. Obras de arte como Assim falou Zaratustra podem dar mostras de uma manifestação estética alcançada por um indivíduo empoderado, que com ponderada atenção para a forma imprimiu ao material sua estampa, servindo-se dela, em todo caso, para sua crítica es- tética fundamental.

Abrangentes manipulações devem ser feitas à filosofia e à estética de Nietzsche para que uma tal estética da existência possa ser a ele atribuída: o conceito de forma estética deve ser conformado ao leito de Procusto, isto é, a exigências de coerência ética, para que então os filósofos da arte da vida [Philosophen der Lebenskunst] possam manuseá-lo. A hipótese fundamental de Nietzsche, segundo a qual o sujeito não é "dono de si próprio", tem aí que ser posta de lado. A proposta de se pensar como nossa vida toma forma opera necessariamente com o pressuposto de uma livre escolha do sujeito e de um domínio, de uma formatação ou pelo menos de uma capacidade de conduzir os impulsos vitais. Esquece-se aí o que Nietzsche sempre e continuamente suponha: "és [algo] feito! Em cada instante! A humanidade trocou ao longo dos tempos o Activum [voz ativa] e o Passivum [voz passiva], seu eterno lapso gramatical" (Aurora 20). Assim sucumbe-se à "sedução da linguagem (e aos mais fundamentais erros da razão nela encravados), a de que se entende ou se mal-entende que todo causar efeito [Wirken] está condicionado por algo que o causa [Wirkende],

${ }^{52}$ Sobre isso, ver: ZITTEL, C. Das ästhetische Kalkül, acima citado. 
por um "sujeito" [...], "aquele que causa a ação [der Thäter]" é simplesmente, no que tange ao fazer [zum Thun], fabulado [hinzugedichtet], — o fazer é tudo" (Genealogia da moral I 13). Para os éticos que concebem esteticamente o dar-se-para-si-uma-forma é necessário assumir um ideal críticocognitivo de totalidade e unidade enquanto critério ético-estético, algo esteticamente antiquado para o caso de Nietzsche. 
